\title{
A Dignidade da Pessoa Humana, a Boa-Fé Objetiva e a Funcão Social do Contrato
}

\author{
The Dignity of the Human Person, the Objective Good Faith and the Social Contract Function
}

\author{
Romano Deluque Júnior ; Cristiane Maluf Rodrigues Correia ${ }^{\mathrm{a}}$
}

aUniversidade Anahnaguera Uniderp. MS, Brasil.

*E-mail: romanodeluque@gmail.com

\begin{abstract}
Resumo
À luz de uma reflexão jusfilosófica, a pessoa humana ascende enquanto sujeito de maior relevância para a ciência do Direito, nesse mesmo sentido, se faz relevante citar que o Direito possuiria, em todas as suas instâncias, a seguinte preocupação: de caminhar paralelamente a um verdadeiro senso de justiça, que se volte à solidariedade e ao bem comum. O presente artigo possui como objetivo fazer emergir uma reflexão ética acerca da função social dos contratos, por sua vez aqui percebida tal como um instituto norteador das relações jurídicas contratuais relacionando-a com a questão da dignidade da pessoa humana enquanto basilar princípio constitucional. A discussão proposta decorrer-se-á de modo a defender a premissa de que a manutenção e a defesa dessa dignidade ocorreriam dentro de uma perspectiva contratualista, a partir da observância e do respeito pelos limites impostos pela própria função social dos contratos, na figura da probidade contratual, da boa-fé objetiva, e da defesa dos interesses difusos e institucionais. Propõe-se, ainda, discutir a respeito de uma ética contratual contemporânea, que a partir dos conceitos aqui em análise, possuiria o intento de superar o ciclo histórico de individualismo exacerbado, e substituí-lo pelo ideal da coexistencialidade. Nessa nova perspectiva ter-se-á em pauta o instituto da boa-fé objetiva, através da qual a relação negocial passaria a ser vislumbrada a partir de uma ética do comum proveito, que caminharia, não obstante, à harmonia jurídico-contratual em prol da coletividade e dos interesses difusos.
\end{abstract}

Palavras-chave: Função Social do Contrato. Contratos. Direito Civil.

\begin{abstract}
On the light of a jus-philosophical reflection, the human being ascends as a subject of greater relevance to the science of Law, in the same sense, it is relevant to mention that Law would have, in all its instances, the following concern: to walk in parallel to a true sense of justice, to return, to solidarity and to the common good. The purpose of this article is to make an ethical reflection about the social function of contracts, in turn perceived here as an institute guiding contractual legal relationships regarding the issue of the dignity of the human person as a basis for constitutional principle. The proposed discussion will be carried out in such a way as to defend the premise that the maintenance and defense of this dignity would take place, from a contractual perspective, from the observance and respect for the limits imposed by the social function of the contracts themselves, figure of contractual probity, objective good faith, and defense of diffuse and institutional interests. It is also proposed to discuss a contemporary contractual ethic that, based on the concepts analyzed here, would attempt to overcome the historical cycle of exacerbated individualism and replace it with the ideal of coexistentiality. In this new perspective, the institute of objective good faith, through which the negotiating relationship would be perceived from an ethic of common advantage, would nevertheless follow the legalcontractual harmony in collective and diffuse interests.
\end{abstract}

Keywords: Social Function of Contract. Contracts. Civil Law.

\section{Introdução}

O Direito se apresenta na sociedade de hoje tal como uma ciência em plena evidência, é talvez o campo acadêmico mais observado e vigiado pelos olhares sociais e da mídia. Tornouse espaço de discussão e de apreciação para os mais variados temas, em que hard cases trazem a tona discussões sobre aborto, eutanásia, liberdade de expressão, crimes digitais, entre outros. A lista é longa. Dentro da perspectiva civilista a situação não é diferente, percebe-se a ocorrência de verdadeira mitigação da autonomia da vontade de contratar para dar espaço a institutos jurídicos, cujo intuito seja a valorização e o respeito pela pessoa humana e manutenção da ordem social e dos direitos difusos e institucionais.

No contexto das garantias constitucionais e, à luz da reflexão jusfilosófica, a pessoa humana ascende enquanto sujeito de maior relevância por parte da ciência do Direito, sendo, portanto, cabível inferir que os princípios constitucionais encontram sua razão e origem no homem (ANDRADE, 2003). O homem é, não obstante, o fundamento de todos os princípios e garantias individuais, pois justificalhes a existência e lhes confere função pragmática e social, é assim, sua matéria-prima. De toda sorte não há como se falar de princípios constitucionais sem se referir também ao seu objeto primeiro, o ser humano. A Constituição Federal de 1988 se constitui, inclusive, tal como primeira linha de defesa do ser humano, resguardando também o direito sobre o uso de bens públicos, essenciais para a qualidade e dignidade da vida humana (BAILO; VIOLA; MARICHAL, 2018).

Nessa mesma concordância cumpre dizer que ao homem é 
conferida relevância sine qua non diante do Direito, tal como o se conhece enquanto ciência. O mesmo se apresenta ainda, enquanto força originária de todas as fontes do Direito, sejam essas positivadas, sejam oriundas de enraizado sistema de crenças culturais, ou mesmo emergidas daquilo que se entende por bons costumes. Logo, o estudo da ciência do Direito seria, pois, um estudo do homem em si, compreendido a partir de sua integralidade subjetiva, e contextualizado junto ao seu meio social, pois somente a partir da realidade jurídica concreta e do caso em análise se vislumbraria a aplicação e a verdadeira utilidade das normas jurídicas. Desse modo, recai sob seus operadores a importante função de discutir e de resguardar os valores que são ao ser humano mais importantes, ou seja, trata-se do verdadeiro garantir dos seus direitos e da crítica reflexão a respeito de seus deveres.

Poder-se-ia dizer, com razoável segurança, que a ciência do Direito possui, em todas as suas instâncias, o seguinte pressuposto: de caminhar paralelamente a um verdadeiro senso de justiça, que flerte junto à solidariedade e ao bem comum. Seria sua função, então, fazer valer a justiça na forma de suas múltiplas tutelas existentes, nesse mesmo sentido é que se afirma que a construção de uma reflexão que possa aproximar as Ciências Jurídicas da pessoa humana se mostra justa e necessária. Uma reflexão ético-jurídica contemporânea deve levar em conta as alteridades que as decisões judiciais podem trazer para a realidade do homem junto de suas mais reais fragilidades, tais decisões devem ser construídas de modo a trazer equilíbrio nas relações jurídicas existentes e a resguardar a dignidade humana e o mínimo existencial nessas mesmas relações

Aquele que toma o Direito como objeto de estudo e reflexão fica evidenciado que a questão da dignidade humana vem ganhando relevância e reconhecimento, tanto nacional, como internacionalmente (BARROSO, 2012). Percebe-se a atuação, ao menos em forma de discurso, de um verdadeiro resguardar da dignidade da pessoa humana, que transcende o universo jurídico nacional. Tratar-se-ia, pois, de um movimento em prol de uma globalização jurídica conceitual, que fortalece o tema da dignidade humana, e o aproxima de algo, tal como uma máxima jurídica a ser seguida e interpretada. Assim, reitera a necessidade de um verdadeiro resguardar da dignidade do homem e do cidadão, e faz com que o tema transcenda os cenários jurídicos nacionais. Um efeito de caráter positivo no que tange ao aplicar de um Direito universal mais justo e humanizado.

Ao se observar a atenção proferida ao tema pela literatura e pela jurisprudência é indissociável ligação entre dignidade da pessoa humana e os direitos humanos e fundamentais reconhecidos, muito embora a menção da dignidade da pessoa humana, enquanto matriz constitucional ou pressuposto acerca dos direitos fundamentais erigidos na Constituição Federal seja bastante recente (MARINONI; SARLET; MITIDIERO, 2017).
Convém dizer que tão somente por integrar, em essência, o gênero humano, já se torna o homem detentor de dignidade. Trata-se de um valor universal inerente a todos, independentemente de caraterísticas físicas ou de perspectivas socioculturais que concernem ao indivíduo (ANDRADE, 2003). Para Sarlet (2012), mesmo aquele que perdeu a consciência da própria dignidade merece tê-la considerada e respeitada.

Ao observar as nuances do cotidiano, é possível perceber que o problema da dignidade humana não se reduz ao desconhecimento do próprio conceito etimológico, tampouco o tema é visto como figura de menor importância ou de segunda categoria. O problema da dignidade é pragmático, que surge diante e a partir da situação ou caso concreto que existiu no passado e reflete diante do presente ou que existe no presente e causa preocupações para o futuro.

No contexto das reflexões a respeito da dignidade humana, à luz do Direito privado contemporâneo, a função social dos contratos emerge, a partir da boa civilística, como objeto de profundo debate no que diz respeito à manutenção dessa mesma dignidade, agora dentro da agenda contratualista. É diante dessa realidade, de dualidades, de ambivalências e de dúvidas que compõem o cenário da teoria e da prática do direito no palco contemporâneo das famílias jurídicas, que o debate acerca da dignidade da pessoa humana como pressuposto à função social dos contratos se faz necessário e relevante (FACHIN, 2015).

A função social do contrato, enquanto relevante instituto contratualista, possui a função de moderar e limitar as relações jurídicas de caráter negocial, de modo a fazer valer, diante de tais relações, e a partir dos princípios da boa-fé objetiva e da probidade contratual, a defesa de interesses institucionais e difusos (FARIAS; ROSENVALD; BRAGA NETTO, 2019; TARTUCE, 2018). Anote-se que tamanha a relevância do princípio, que o mesmo é aplicável para todas as espécies de relações jurídicas, quer contratuais ou extracontratuais, tanto de direito privado quanto público (FACHIN, 2015). É considerada, ainda, um preceito de ordem pública, pois visa defender os interesses de terceiros, que porventura estejam a alcance das influências dos efeitos de um determinado contrato.

Anote-se que a função social do contrato é contemplada, em normativa infraconstitucional, no Código Civil de 2002, tanto na figura do art. 421, quanto na do art. 2.035, e este último irá dispor sobre sua eficácia no tempo. Cabe citar que a nova legislação traz como saliente característica forte teor social, no qual a liberdade de contratar é mitigada pelo alcance social dessa mesma contratação (REZENDE; ZYLBERSZTAJN, 2011).

Verifica-se que as bases conceituais da função social do contrato, que serão aprofundadas posteriormente, são amplas, e por consequência, imprecisas. Soerguem-se ora amarradas à quebra do individualismo, ora à cláusula geral 
de solidariedade (NALIN, 2002), sempre com o intuito de promover a igualdade substancial na relação contratual e o equilíbrio entre as parcelas, bem como o de contrapor-se ao enriquecimento sem causa.

O presente artigo tem como objetivo primeiro conduzir uma reflexão ética acerca da função social dos contratos, aqui entendida tal como um instituto norteador das relações jurídicas contratuais. Propõe-se correlacionar essa mesma temática junto à questão da dignidade da pessoa humana, aqui entendida por sua vez, enquanto basilar princípio constitucional, de modo a defender a premissa de que a manutenção e a defesa dessa dignidade se daria dentro de uma perspectiva contratualista, a partir da observância e do respeito pelos limites impostos pela própria função social dos contratos, na figura da probidade contratual, da boa-fé objetiva, e da defesa dos interesses difusos e coletivos.

Nesse contexto se objetiva promover um debate a respeito da ética contratual contemporânea, que a partir dos conceitos aqui em análise possuiria o intento de superar o ciclo histórico do individualismo exacerbado, substituindo-o pela coexistencialidade (FACHIN, 2015). Então, a relação negocial passaria a ser percebida a partir da de uma ética do comum proveito, que caminharia, não obstante, a harmonia jurídico-contratual em prol da coletividade.

$\mathrm{Na}$ perspectiva jurídica contemporânea, de ênfase à solidariedade contratual e de respeito às diretrizes e preceitos da boa-fé objetiva, é que atingir o equilíbrio entre justiça e segurança jurídica se revela tal como um desafio. Este que imbui em si mesmo a tarefa de interpretar e decodificar os componentes textuais presentes nos contratos em geral, bem como nas leis que os regulam, sem que essa interpretação se restrinja à superficial análise feita a partir da dogmática jurídica ortodoxa (FACHIN, 2015).

\section{Desenvolvimento}

\subsection{A Dignidade Humana Enquanto Pressuposto Necessário do Pensar Jurídico}

Diante de uma reflexão sobre as mais relevantes problemáticas jurídicas da contemporaneidade, a ideia de dignidade humana ascende enquanto figura de linguagem possuidora de caráter multifacetado. É pois utilizada como ponto de apoio por lados opostos de uma mesma discussão, além de ser mencionada nos mais diversos documentos internacionais, em múltiplas leis, e em várias constituições mundo afora (BARROSO, 2012; LOPES, 2000). Trata-se, sem dúvida, de uma das maiores "cartas coringa" em uso no direito contemporâneo, sendo de relevante conveniência, então, propor uma discussão profunda com o intuito de lançar luz e desmistificar o seu real significado.

Sua origem histórica remete, primeiramente à Roma antiga, atravessando a Idade Média, até o surgimento do Estado Liberal, nesse contexto, o conceito remeteria a uma ideia de status pessoal ou à proeminência de determinadas posições sociais (BARROSO, 2012). Relacionava-se assim, a um sentido de categorização da sociedade, na qual ser digno significava ser nobre, ou possuir prerrogativas especiais, como direitos e privilégios, posteriormente, adquire uma tipicidade cristã a partir da obra de Agostinho e Tomás de Aquino que viria a se relacionar a um valor moral e espiritual, no que tange à responsabilidade pelos próprios atos e condutas (GONÇALVES; LOPES, 2013).

Atualmente, a dignidade humana se assenta sob o pressuposto de que cada ser humano é portador de um valor intrínseco (BARBOSA; COSTA, 2016), e esse sentido é fundamentado por todo um aparato de concepções filosóficas e religiosas. A evolução conceitual do tema passou por processos que acabaram por talhá-lo tal como é concebido atualmente, cite-se, nesse contexto, as influências oriundas do Iluminismo, bem como outras resultadas a partir do fim das duas grandes guerras mundiais, e com o advento da Liga das Nações e da Organização das Nações Unidas, respectivamente.

A partir da segunda metade do século XX, com o reconstruir de um mundo estruturalmente devastado pela guerra, e moralmente assombrado pelo espectro do genocídio promovido pelos nazistas, chega-se a hora de se utilizar recursos e criar estratégias cuja finalidade seria o de previnir condutas contrárias à dignidade e ao valor humano.

A inclusão dos primeiros tratados e documentos internacionais em diversas constituições mundo afora marcouse como o primeiro passo para a importação da dignidade humana para o universo jurídico mundial. O segundo grande passo ocorreu de maneira bem mais sutil, tratou-se na realidade de uma mudança sociocultural em relação ao pensar jurídico, no sentido de que esse novo pensar havia acabado por afastar o Direito de uma cultura jurídica positivista e, consequentemente, abrindo espaço para uma aproximação das Ciências Jurídicas na direção de um pensar filosófico preocupado com a ética e a moral.

Corroborando com o disposto, Barroso (2012, p. 8) expõe:

Nessa teoria jurídica renovada, na qual a interpretação das normas legais é fortemente influenciada por fatos sociais e valores éticos, a dignidade humana desempenha um papel proeminente. Conclui-se aqui, então, o breve esboço da trajetória religiosa, filosófica, política e jurídica da dignidade humana em direção ao seu sentido contemporâneo.

Assim se percebe que, em se tratando do resguardar da dignidade humana, vê-se diante de um dos maiores exemplos de concordância ética do direito moderno, cabe ainda dizer que, no plano abstrato, poucas ideias se equiparam a essa na capacidade de encantar o espírito e ganhar adesão unânime, porém há de se evitar a banalização conceitual do tema, pois em termos práticos, a dignidade, enquanto conceito jurídico, acaba por funcionar como mero espelho, no qual cada um projeta os seus próprios valores (BARROSO, 2012). Portanto, há que se proceder junto à individuação do conceito, para que o mesmo não situe limitado a um ideal romântico de si mesmo.

É importante, no entanto, identificar diretrizes quanto à 
utilização do sintagma dignidade humana, pois o mesmo é utilizado desnecessariamente e, em larga escala, sendo por vezes invocado em causa própria, qualquer que seja essa.

Não é por acaso, assim, que a dignidade, pelo mundo afora, tem sido invocada pelos dois lados em disputa, em matérias como aborto, eutanásia, suicídio assistido, uniões homoafetivas, hate speech (manifestações de ódio a grupos determinados, em razão de raça, religião, orientação sexual ou qualquer outro fator), clonagem, engenharia genética, cirurgias de mudança de sexo, prostituição, descriminalização das drogas, abate de aviões sequestrados, proteção contra a autoincriminação, pena de morte, prisão perpétua, uso de detector de mentiras, greve de fome e exigibilidade de direitos sociais. A lista é longa (BARROSO, 2012, p.4).

Resta claro que a ideia da dignidade humana está, como qualquer outra ideia complexa, sujeita à má utilização e ao abuso por parte de seus intérpretes. O problema reside junto aos riscos quanto a sua utilização, no sentido de que essa pode ajudar a embasar ideais tirânicos e mal intencionados, tudo em nome da dignidade de um povo, ou do bem-estar coletivo. A história não se cansa de demonstrar junto aos contundentes exemplos, como os mais nobres ideais podem ser distorcidos em prol de interesses egoísticos e pouco preocupados com a dignidade de fato.

O filósofo e jurista estadunidense Ronald Dworkin (2011) traduz a relevância do conceito enquanto figura fundamental no apoio às decisões eticamente embasadas e para um procedimento judicial verdadeiro, que se volte para a aplicação de justiça frente à fragilidade humana. Afirma ser lamentável abandonar uma ideia relevante pelo risco de equívocos por parte de alguns. Trata-se de encontrar, em meio a tantas e complexas variáveis, uma gramática mínima no que tange à dignidade humana, para que essa possa emergir enquanto um conceito robusto e eloquente. Seu conceito deve, ainda, ser "compatível com o livre arbítrio, com a democracia e com os valores seculares" (BARROSO, 2012, p. 24). O problema da dignidade humana é, sobretudo, um problema relacionado à falta de autonomia em que o valor intrínseco da vida humana é ameaçado ou violado por si ou pelo outro (BARBOSA; COSTA, 2016).

Anote-se que o adequado entendimento acerca da dignidade humana só pode ser atingido a partir de uma intensa e constante discussão, que envolva desde o mais renomado jurista até o mais singelo, em matéria de conteúdo jurídico, estudante de Direito. O problema da dignidade é pois a sua ausência e se manifesta quando em favor de interesses individuais, põe-se abaixo direitos alheios ou, simplesmente, deixa-se de percebê-los.

Inserir o tema da dignidade humana na formação acadêmica é um pressuposto para um pensar jurídico humanizado e contemporâneo, essa inserção deve se dar de modo que o tema seja debatido intensa e vigorosamente. Necessita assim, abandonar o lugar comum, e descer do pedestal de ideal romântico que lhe foi imposto, para que passe a se manifestar concretamente no pensamento dos operadores e intérpretes do
Direito e possa, dessa forma, alterar de maneira pragmática a realidade jurídica concreta, na qual esses indivíduos atuam ou virão a atuar no futuro.

Para além da dignidade humana, em seu sentido romântico, é trazida a tarefa de pensá-la tal como um princípio jurídico e, nesse sentido, 'há um razoável consenso de que ela constitui um valor fundamental subjacente às democracias constitucionais de modo geral”, porém, não se apresenta como uma figura absoluta no ordenamento jurídico, havendo situações nas quais essa terá de ceder para que se abra espaço para outros valores basilares, como a segurança jurídica, por exemplo (BARROSO, 2012). Nesse sentido, o autor assevera:

Como regra geral, no direito não há espaço para absolutos. Embora seja razoável afirmar que a dignidade humana normalmente deve prevalecer, existem situações inevitáveis em que ela terá de ceder, ao menos parcialmente. Um exemplo evidente de uma dessas situações ocorre quando alguém é condenado à prisão após um procedimento condizente com o devido processo legal: nesse caso, um componente importante da dignidade dessa pessoa - representado por sua liberdade de ir e vir - é restringido (BARROSO, 2012, p.25).

Assim, vislumbrando-se juridicamente a dignidade humana enquanto valor se vê que esta é fundamental, porém não absoluta. É talvez o mais basilar dos princípios constitucionais, entretanto, cumpre-se dizer, merece parcimônia e reflexão diante do caso concreto ou do contexto teórico-jurídico em pauta.

Por este vértice, é chegado um ponto de reflexão neste debate. Ao se contemplar o tema da dignidade, tal como um pressuposto do pensamento jurídico, tem-se por intuito dizer que: o princípio da dignidade humana deve emergir enquanto objeto de ponderação junto da realidade a que se destina o respectivo pensar, e não como uma cláusula máxima a ser alcançada a qualquer custo.

Tal reflexão deve ocorrer através de uma ótica que contemple a situação concreta, aqui objeto do pensar jurídico, a partir de um pensamento ético que seja tecnicamente embasado, e ao mesmo tempo, humanizado. Para Dworkin (2011), princípios constitucionais não são regras e, portanto, não são passíveis de serem aplicados em forma de tudo ou nada. Trata-se, de acordo com Barroso (2012), de figuras imbuídas de caráter motivador para a criação de normas, pois nessas estão contidas exigências de justiça ou equidade ou outra exigência de moralidade que quanto as possibilidades de aplicação do tema da dignidade humana.

Assim, se faz imperioso lembrar que princípios possuem peso e relevância jurídica, mas necessitam da realidade e da norma para lhes proporcionar sentido e existência. É razoável a afirmação de que um princípio constitucional possui a utilidade principal de se prestar integralmente à dignidade da figura motivadora do próprio existir da Constituição Federal, o homem. E nesse contexto, o princípio pode servir de peso e de medida, tanto na elaboração de leis, quanto de embase às decisões judiciais éticas e responsáveis.

O filósofo do Direito alemão Robert Alexy (2004), aqui é 
trazido por Barroso (2012), considera os princípios tais como mandados de otimização, cuja aplicação depende de critérios de proporcionalidade junto à análise dos fatos concretos, podendo, inclusive, vir a ceder em virtude de elementos contrapostos. Em cada realidade jurídica específica, os princípios constitucionais mobilizam e criam regras de conduta que far-se-ão eficazes diante das particularidades do respectivo caso concreto, que carregam, portanto, dentro de si um núcleo de caráter altamente abstrato, porém dotado de imenso poder de alteridade.

O fato é que em uma situação de ambiguidade jurídica, ou diante de um caso complexo que envolva, por vezes, lacunas do ordenamento jurídico, a dignidade humana deverá servir de norte à formulação de entendimentos e, posteriormente, à tomada de decisões. Trata-se de um instrumento pelo qual o indivíduo na função de operador do direito deve se guiar na direção do mais ético e humanizado ideal de justiça.

É evidente que diante de tais casos podem vir a ocorrer conflitos de normas e colisões entre direitos coletivos e individuais, o que é natural diante de tão extenso campo de atuação da ciência do Direito, de toda sorte parece que a ideia de se utilizar o valor da dignidade humana, tal como um ideal de reflexão a ser resguardado em seu fim último, uma boa forma de se conduzir todo e qualquer debate cuja temática de centro seja o homem.

Enquanto princípio constitucional, a dignidade humana pode precisar ser ponderada com outros princípios ou metas coletivas, pois a partir de casos complexos advirão impasses lógicos, e um choque de absolutos não tem solução. O que pode ser defendido até o fim é que tal valor deve ter procedência na maior parte dos casos, mas não em todos, e ainda que a partir dessa ponderação ética, e diante do respectivo contexto político e cultural, o pensar jurídico deve se manifestar de maneira reflexiva e responsável.

Nesse mesmo sentido convém reafirmar a dignidade humana como um princípio e um valor fundamental, que deve constantemente permear o pensar jurídico, deve ainda, moldar-lhe a feição com o intuito de torná-lo mais humano e ponderado, e ainda, não obstante, mais atento na busca de verdadeira justiça ética e solidária.

Dentro da temática contratualista não é exagero dizer que a dignidade humana emerge em um sentido de embase para respectiva função social que possuí o tema. Isso significa que, a partir do entendimento de Calixto Salomão Filho (2004), a aplicação do princípio da função social do contrato deve ser considerada sempre que o contrato puder afetar de forma interesses institucionais externos a esse, logo, o conceito é construído a partir de um interesse de proteção junto aos interesses difusos e da coletividade.

Ora, se a função social do contrato possui característica mitigante e de proteção, que se relaciona aos efeitos de um determinado contrato junto aos indivíduos externos a ele, logo, a proteção desses mesmos interesses soergueria-se tal como matéria de dignidade humana, pois significaria, pragmaticamente, um robusto defender dos interesses daqueles que se situam às margens de determinado contrato, mas sujeitos aos seus efeitos. Trataria-se de impedir a lesão de interesses difusos e coletivos, e em caso de adimplido o contrato e efetivado os seus efeitos, garantir a reparação por meio de atribuição de responsabilidade civil.

\subsection{O Papel da Boa-Fé Objetiva Enquanto Matriz Ética de Probidade Contratual}

Tal como a dignidade humana, a expressão "boa-fé" possui caráter multifacetado e atua nem sempre designando o mesmo fenômeno jurídico. Martins-Costa (2018), em obra definitiva sobre o assunto, percebe que na legislação nacional o conceito assume diversos significados, ora como "conceito indeterminado", ora "como princípio", ora "plasmando uma acepção objetiva" tal como um standard comportamental jurídico, ou com "acepção subjetiva", levando, por vezes, a perceber o termo relacionando-se a alguma crença e/ou estado de ignorância.

Isso quer dizer que, diante da própria lei escrita caberia, não obstante, uma tarefa hermenêutica. Diga-se importante citar alguns exemplos, entre os quais, os art. 113, $167 \S 2^{\circ}$, 422, e 1.201 do Código Civil (C.C.) de 2002 - que trazem em seu cerne, acepções diferentes junto a um mesmo vocábulo (BRASIL, 2008). Veja-se:

Art. 113. Os negócios jurídicos devem ser interpretados conforme a boa-fé e os usos do lugar de sua celebração.

Art. 167. É nulo o negócio jurídico simulado, mas subsistirá o que se dissimulou, se válido for na substância e na forma [...].

$\S 2^{\circ}$ Ressalvam-se os direitos de terceiros de boa-fé em face dos contraentes do negócio jurídico simulado.

Art. 422. Os contratantes são obrigados a guardar, assim na conclusão do contrato, como em sua execução, os princípios de probidade e boa-fé.

Art. 1.201. É de boa-fé a posse, se o possuidor ignora o vício, ou o obstáculo que impede a aquisição da coisa.

É perceptível a diferença de sentido atribuído ao sintagma boa-fé em cada um dos dispositivos supracitados, logo, se vislumbra uma eminente necessidade de proceder junto a uma discussão esclarecedora acerca do conceito aqui em discussão. Se faz importante identificar e distinguir duas funções jurídicas diversas, as quais possuiriam especificidades normativas distintas, a boa-fé subjetiva e a boa-fé objetiva. Tal definição deve ocorrer a priori, para que se possa prosseguir com o trabalho.

Dentro da temática contratualista e obrigacional, o refino coerente destas definições emerge tal como de profunda relevância, pois as mesmas são figuras de constante confusão por parte dos operadores do Direito, tanto os em fases iniciais, como para os mais experientes. Se faz necessária pois uma distinção clara para que o termo se afaste de um ideal de compreensão generalizado, e que assim possa vir a se tornar objeto de profunda reflexão, e de embase para decisões 
difíceis e complexas.

Corroborado com esse entendimento, as seguintes palavras de Martins-Costa (2018, p.43) se fazem pertinentes:

Efetivamente, não é fácil essa caracterização, pois a locução \{boa-fé\} é uma expressão semântica vaga ou aberta e, por isso, carecedora de concretização, sendo a tarefa de concretizar sempre, e necessariamente, contextual.

Diante de um natural desalinho de entendimentos, devese , portanto, tecer algumas considerações, de modo sucinto, porém eficaz, acerca da boa-fé em seu caráter "subjetivo".

Ao se referir ao termo boa-fé (subjetiva) se refere a um estado psicológico que se refere a um "agir em boa-fé". Implica em algo que pode ser compreendido tal como o oposto do "agir em má-fé". Trata-se de um estado emocional íntimo e pessoal, que se relaciona, sobretudo, às intenções subjetivas do indivíduo, sendo, portanto, algo não disponível para aferição objetiva (FARIAS; NELSON; BRAGA NETTO, 2019).

Juridicamente, é possível relacioná-la a um "[...] estado de consciência caracterizado pela ignorância de se estar a lesar direitos ou interesses alheios" tal como referido no art. 686 do C.C. 2002, ou junto da "[...] convicção de estar agindo em bom direito, consoante, por exemplo, a previsão do art. 309”, também do C.C. 2002 (MARTINS-COSTA, 2018, p.279). Cite-se a necessidade de ilustrar o acima descrito com os referidos artigos, veja-se:

Art. 686. A revogação do mandato, notificada somente ao mandatário, não se pode opor aos terceiros que, ignorando-a, de boa-fé com ele trataram; mas ficam salvas ao constituinte as ações que no caso lhe possam caber contra o procurador.

Art. 309. O pagamento feito de boa-fé ao credor putativo é válido, ainda provado depois que não era credor (BRASIL, 2008).

Note-se que em ambos, as conotações, embora distintas, se relacionam a um estado pessoal, e não a uma normativa de conduta.

Em resumo, ao se lidar com a boa-fé subjetiva, é possível observar se tratar da mesma, quando um indivíduo dotado de plena convicção, ainda que em estado de total ignorância, acredita estar cumprindo a lei da forma como lhe parece ser normativamente correto. Tratar-se-á de boa-fé subjetiva, quando se referir ao ato praticado por terceiro que, por crer na licitude e na legitimidade de seu ato, acaba protegido pelo ordenamento jurídico.

Ainda mais relevante para esta discussão é a boa-fé em seu caráter objetivo, essa soergue-se, por sua vez, tal como um instituto ou modelo jurídico. Aqui sim é possível vislumbrar objetivamente, pois se trata, sobretudo, de um "[...] modelo comportamental pelo qual os participantes do tráfico obrigacional devem ajustar o seu mútuo comportamento" (MARTINS-COSTA, 2018, p.281). É, pois, um ideal direcionador de condutas, que diz respeito aos atos jurídicos, principalmente, os de caráter negocial.

Em função do elevado potencial de generalização que possui o termo, se faz uma tarefa difícil a sua sistematização, de modo que diante da análise de um mesmo caso concreto possam advir diferentes pontos de vista no tocante à boa-fé objetiva, o que é compreensível e natural. Assim, condicionase o conteúdo do conceito, indissoluvelmente ligado às circunstâncias e aos fatores vitais determinantes do contexto da sua aplicação.

Por isso é impossível apresentar uma definição apriorista e bem acabada do que seja a boa-fé objetiva. Como sintetizado com precisão, o conceito de boa-fé parece mais interessar por sua função que por sua definição (MARTINS-COSTA, 2018, p.43).

Convém aqui dispô-lo tal como um cânone de interpretação dos contratos (MARTINS-COSTA, 2018), e como um verdadeiro standard comportamental com vistas a identificar comportamentos que, dentro de determinada lide judicial, seriam considerados probos ou ímprobos. Tão logo se afere que agir com boa-fé objetiva concretiza as exigências de probidade, correção e comportamento leal hábeis a viabilizarem adequado tráfego negocial, sempre considerados a partir do negócio jurídico ao qual se vinculam.

Embora de difícil definição técnica, é possível concretizar a boa-fé objetiva no tocante a uma série de fatores comportamentais, que diante de uma relação obrigacional serviriam tal como uma manifestação pragmática deste mesmo modelo de boa-fé, logo, se faz possível presumir que o indivíduo, que guarda consigo tais princípios de comportamento, preza também pela boa fé objetiva em suas relações obrigacionais.

Acerca do acima disposto, anote-se que é responsabilidade do agente em boa-fé (objetiva) prezar pelos princípios relacionados à, "[...] cooperação, informação, proteção e consideração às legítimas expectativas do [...] copartícipe da relação obrigacional" (MARTINS-COSTA, 2018, p.45).

Isso significa que o agir, dentro da esfera contratual junto a tais prerrogativas, que se manifestam, tais como: diretrizes de comportamento diante das relações obrigacionais, faria o contratante incorrer, ao mesmo tempo, em um comportamento amparado pela ética e pela probidade contratual, estando, por consequência, protegido pela lei e pelo ordenamento jurídico como um todo, haja vista que a própria boa-fé objetiva serve como pauta de interpretação, fonte de integração e critério para a correção de condutas contratuais.

É licito então dizer que um determinado contrato deve se pautar, desde a sua idealização, em acordo com o princípio jurídico da boa-fé objetiva, que aqui remete a um estado tido por ideal, no que tange ao modo de atuar de seus respectivos contratantes. De toda sorte parece correta a acepção que tal instituto se refere a um papel dinâmico e observável que será desempenhado, em todas as fases de uma relação obrigacional, pelos sujeitos dessa mesma relação.

Trata-se aqui de instrumento de coordenação das interações sociais que se referem ao tráfego negocial, em que implicaria em um consentir e em um agir de acordo com regras socialmente preestabelecidas, a partir daquilo que 
se entende, a partir de uma sociedade, por bons costumes, confiança mútua e honestidade.

A partir de uma interpretação do Código Civil Alemão BGB de 1896, é possível descrever a boa-fé objetiva tal como um arquétipo jurídico. Como tal, não possui características definidas a priori, mas essas somente se manifestariam junto aos atos praticados diante da realidade jurídico-negocial a que se destinam, bem como no respectivo caso concreto.

Levando na mais alta conta os princípios de honestidade, de lealdade e de probidade, os indivíduos devem moderar suas ações de acordo com o que pede o arquétipo, que traz em si mesmo, os princípios acima descritos, porém de maneira abstrata que se ressalte, somente se concretizarão a partir do agir humano diante de sua realidade negocial.

Nessa esteira, citam-se as palavras do Bürgerliches Gesetzbuch (BGB), o Código Civil Alemão em sua Seção 242, que assim dispõe:

§ 242 Do Agir em Boa-Fé. O sujeito da relação obrigacional possui o dever de agir de acordo com os pré-requisitos da boa-fé, levando em consideração os bons costumes (BUNDESREPUBLIK DEUTSCHLAND, 2002) ${ }^{1}$

De toda sorte, parece se tratar, o instituto da boa-fé objetiva, de um modelo jurídico complexo e prescritivo. Isso significa que o conceito não se manifesta em uma norma isolada e inerte no tempo, mas que se apresenta de maneira complexa, pois articula, finalisticamente, normas provindas de mais de uma das fontes do Direito, como a lei e jurisprudência; ou a lei, o costume e o negócio jurídico; ou ou lei, a jurisprudência e a doutrina. Trata-se de um instituto que pressupõe a combinação de saberes, oriundos de diversas fontes da ciência do Direito com a finalidade última de se manifestar de forma prescritiva, ou seja, a de impor ações, condutas, vedações, sanções, não apenas recomendações ao aplicador do Direito (MARTINSCOSTA, 2018).

Em suma, quando se trata da boa-fé objetiva, faz-se referência ao agir segundo as ordens e preceitos da boa-fé, já subjetivamente falando, a conotação utilizada é o "agir em boa-fé". Frise-se que são institutos distintos e inconfundíveis pela respectiva natureza. Um é estado, o outro é norma.

Retomando o foco no que concerne à relação jurídica obrigacional, as palavras de Judith Martins-Costa (2018, p.285) se fazem relevantes:

Os sujeitos de uma relação jurídica devem agir segundo a boa-fé; devem pautar suas relações pela lealdade; não devem agir de modo deslealmente contraditório; não devem agir torpemente, etc. Se infringirem as normas de dever-ser, sujeitam-se a consequências jurídicas desfavoráveis.

Assim, anote-se que o campo de atuação da boa-fé repousa sob o raio de alcance do Direito Obrigacional, isso significa que o instituto aqui em análise exerce influência no Direito Civil Contratual; de Família e Sucessões; Comercial; Internacional
Privado; Trabalhista; do Consumidor; Administrativo; Tributário; e Previdenciário, todavia, por razões objetivas se reserva aos aspectos obrigacionais oriundos das relações civis contratuais.

Nesse campo, o pressuposto encontra a base em relações obrigacionais consideradas paritárias, isto é, sem partes hiper ou hipossuficientes. Isso significa que as partes possuem condições simétricas, ressalvados eventuais defeitos, quanto ao exercício do poder negocial. Nesse contexto, a boa-fé atuará de maneira a permear a liberdade de contratar, sendo assim, haveria mais espaço para o exercício da autonomia privada e, consequentemente, maior é o peso da autorresponsabilidade, contrapartida necessária da mesma autonomia (MARTINSCOSTA, 2018).

Existe aqui a presunção de igualdade entre as partes e, simultaneamente a esse entendimento, existe também um investimento de confiança no copartícipe obrigacional, de que esse irá adimplir adequadamente junto a sua prestação devida, tal sentimento é legitimamente suscitado em direção à outra parte, criando-se uma objetivada expectativa quanto ao seu comprometimento.

A partir da expectativa pelo cumprimento da obrigação nasce também a confiança, essa, que por sua vez constitui o cerne de todo Negócio Jurídico. Do atravessamento entre o objetivável elemento volitivo e a confiança suscitada pela promessa de cumprimento nasce a justificativa material da autonomia privada. Desse modo, se há confiança, há também expectativa de que a outra parte atue de acordo com os princípios da boa-fé objetiva, eis a relevância da autorresponsabilidade. Nesse sentido, Martins-Costa (2018, p.292) explica:

O comportamento segundo a boa-fé tomará então, prima facie, feição de uma conduta contratual pautada pela lealdade, coerência e correção (probidade), o que não ofusca a circunstância de, em vista da heterogeneidade dessas relações, a boa-fé manifestar-se em vários e distintos níveis de intensidade.

Anote-se que diante da inter-relação entre boa fé, confiança, autonomia privada e autorresponsabilidade, decorrem às partes deveres anexos de cooperação (MARTINS-COSTA, 2018), não somente no que tange à coerência comportamental, mas também aos que relacionam às obrigações informativas e de proteção, para que o contratante, agindo em boa-fé, não seja prejudicado a partir desse mesmo contrato.

Por fim, a partir da relação dialética, porém de justaposição, entre os princípios de boa-fé objetiva e da autonomia privada, os deveres de cooperação entre as partes serão analisados, sempre à luz da espécie de negócio jurídico no qual as partes se encontram. Trata-se de efeito moderador que visa o adequado cumprimento obrigacional e que inibe o enriquecimento sem causa e a onerosidade excessiva dos contratos, nesse sentido,

1 Cf. Origunal: $\S 242$ Leistung nach Treu und Glauben: Der Schuldner ist verpflichtet, die Leistung so zu bewirken, wie Treu und Glauben mit Rücksicht auf die Verkehrssitte es erfordern. 
o art. 478 se faz exemplificativo, veja-se.

Art. 478. Nos contratos de execução continuada ou diferida, se a prestação de uma das partes se tornar excessivamente onerosa, com extrema vantagem para a outra, em virtude de acontecimentos extraordinários e imprevisíveis, poderá o devedor pedir a resolução do contrato. Os efeitos da sentença que a decretar retroagirão à data da citação.

Como exemplifica o dispositivo supracitado se faz correta a afirmação de que o alcance do princípio da boa-fé objetiva se encontra indissoluvelmente ligado à concretude jurídica na qual se encontra o caso em análise, todavia, suscitar uma embasada discussão, acerca de todo e qualquer dilema negociatório à clara luz da boa-fé objetiva, não parece bastante oportuno.

\subsection{A Função Social do Contrato Enquanto Diretriz Ética da Liberdade de Contratar}

Conforme ja foi dito, a Função Social do Contrato é disciplinada no ordenamento jurídico a partir do art. 421 do C.C. de 2002 (BRASIL, 2008). É natural que ao se observar o supracitado artigo se perceba o quão abrangente e complexa pode ser sua tarefa interpretativa, assim, se faz necessária uma discussão com ênfase a um refinamento conceitual do mesmo, de modo que a expressão em pauta possa ser vislumbrada à margem de concepções pouco pensadas e precocemente concebidas.

Nesse mesmo sentido, um correto entendimento acerca do vocábulo contrato se faz necessário, e esse citando Rosenvald (2007), quando afirma que, contemporaneamente, o contrato pode ser conceituado tal como instrumento de tutela à pessoa humana, suporte para o livre desenvolvimento de sua existência, inserindo-se a pessoa na diretriz de solidariedade. Assim, o estar para o outro se converte em linha Hermenêutica de todas situações patrimoniais. Trata-se de instrumento de manifestação da autonomia privada, do direito atribuído ao homem de fazer negócios e positivá-los de modo expresso, servindo ainda de suporte e tutela para o resguardo de direitos e à cobrança de responsabilidades para com seus partícipes.

O entendimento da Função Social do Contrato perpassa por uma nova concepção do próprio conceito de contrato, e este, por sua vez, ganha atributos e características relacionadas à solidariedade entre os indivíduos, como preceitua a C.F. de 1988 em seu art. $3^{\circ}$, quando dispõe:

Art. $3^{\circ}$ Constituem objetivos fundamentais da República Federativa do Brasil;

I - construir uma sociedade livre, justa e solidária. (BRASIL; ASSEMBLEIA NACIONAL CONSTITUINTE, 1988)

A partir dessa matriz solidária, desse estar para o outro, pouco a pouco o direito privado foi perdendo caraterísticas segregacionistas para caminhar rumo a um ideal renovado da autonomia de vontade, no qual o ser humano, outrora considerado figura objetiva da relação negocial, ascende como valor, fundamento e fim da ordem jurídica (ROSENVALD, 2007). Mitiga-se o princípio da autonomia de vontade para dar espaço para a autonomia privada resguardada pelo princípio constitucional da dignidade humana (art. $1^{\text {o }}$, III C.F.), já aqui citado, e da Ordem Econômica (art. 170, C.F.), esse último assim descrito:

Art. 170. A ordem econômica, fundada na valorização do trabalho humano e na livre iniciativa, tem por fim assegurar a todos existência digna, conforme os ditames da justiça social, observados os seguintes princípios:

I - soberania nacional;

II - propriedade privada;

III - função social da propriedade;

IV - livre concorrência;

$\mathrm{V}$ - defesa do consumidor;

VI - defesa do meio ambiente, inclusive mediante tratamento diferenciado conforme o impacto ambiental dos produtos e serviços e de seus processos de elaboração e prestação [...]. (BRASIL, 1988)

Cumpre-se dizer que o referido artigo possui função de articular a aplicação das normas jurídicas junto à autonomia negocial, de modo a talhar-lhes uma feição mais solidária e humanizada. Não se trata pois, da perda de autonomia, mas do legítimo resguardar da dignidade dos partícipes da relação contratual, dos terceiros envolvidos, bem como da sociedade na qual os mesmos se encontram inseridos. Desse solidarismo constitucional advém a Função Social do Contrato, tal como hoje se vislumbra.

É ainda possível afirmar que junto dessa nova concepção de liberdade contratual, outros dois princípios foram a essa relacionados: a boa-fé objetiva e o equilíbrio contratual. Ambos vêm para complementar e relativizar as relações contratuais humanas, ou nas palavras de Nelson Rosenvald (2007, p.11), os mesmos “ não restringem a autonomia privada, pelo contrário: valorizam-na, equilibrando aquilo que a realidade crua tratou de desigualar, afinal, o poder de vontade de uns é maior que de outros.

Não há como deixar de ressaltar a mais básica finalidade dos contratos, a de se fazer fonte de obrigações junto de suas partes diretamente envolvidas quanto ao seu adimplemento, tal é o fator supra relevante que resulta na manifestação da autonomia privada. $\mathrm{O}$ direito de negociar é inerente a todos e garantido pelo Estado, é ainda um adequado instrumento de fomento econômico e mercantil de uma sociedade, pois permite o fluxo e a troca de titularidades bem como possibilita, com base na confiança alicerçada entre as partes, o benefício mútuo que se origina das transações econômicas oriundas das relações intersubjetivas.

Frise-se que o sistema contratual, tal como hoje se concebe, não é estanque, muito menos fechado é, além de um instrumento de manifestação dos interesses individuais, "[...] um mecanismo de promoção dos objetivos da ordem jurídico-constitucional” (MATTIETTO, 2005, p.208), que por sua vez contempla expressamente a função social como um dos princípios da constituição econômica de sociedade, como consta no já supracitado art. 170 da Constituição Federal de 1988.

Cabe dizer que a função social do contrato, trazida pelo art. 
421 do novo C.C. de 2002, vem para por termo à concepção contratualista na qual os contratantes são percebidos tal como uma ilha isolada, distante de tudo e de todos, para dar lugar a um novo entendimento sobre o tema, em que o contrato passa a ser vislumbrado como algo maior, gerando, a depender de seu conteúdo, e em maior ou menor proporção, efeito para terceiros. É a proteção a esses terceiros não envolvidos na estrutura contratual interna que o ordenamento jurídico se propõe a estabelecer, de modo que o contrato possa e deva ser elaborado, levando em plena conta as consequências de tais efeitos.

Resta atribuir clareza e identificar quem de fato são esses terceiros, que tanto devem ser protegidos na seara contratual, e diga-se sem o preenchimento desses atributos a previsão constante no art. 421 do C.C. se arrisca a um vazio conceitual.

Segundo Salomão Filho (2004, p.6), esses efeitos sociais do contrato nada mais são que: "[...] a identificação dos interesses de terceiros dignos de tutela e passíveis de serem afetados pelas relações contratuais", evidentemente, tal assertiva é ainda genérica, portanto, propensa a uma tarefa hermenêutica no sentido de sua ampliação. Nesse sentido convémafirmar que o mero envolvimento de terceiros não se faz suficiente para justificar tão importante função, sendo por demais vaga e imprecisa. Segundo o autor, o correto entendimento do objeto desta discussão perpassa pela noção de interesses institucionais.

No Estado moderno, não é mais possível admitir que existam apenas, de um lado, regras de proteção a direitos individuais econômicos e, de outro, apenas normas-objetivo, fins e objetivos do processo econômico. As primeiras, como por exemplo o direito de propriedade, típicas do Estado liberal, são insuficientes para atender às necessidades de natureza coletiva, típicas da sociedade atual (SALOMÃO FILHO, 2004, p.7).

É preciso reconhecer a necessidade de normas possuidoras de caráter meta-individuais, que alcancem além dos limites da individualidade do próprio ser humano, e que não sejam, simultaneamente, uma mera extensão dos direitos e garantias individuais, uma vez mais a doutrina alemã é pioneira ao desenvolver de maneira rica e satisfatória o conceito de garantias institucionais, esse por sua vez perpassa pela teoria das Schutzgesetze, ou normas de proteção (SALOMÃO FILHO, 2004). É originada na seção 823 do BGB, que assim declara:

§ 823 Responsabilidade em danos

(1) Uma pessoa que, intencionalmente ou por negligência, lesione ilegalmente a vida, corpo, saúde, liberdade, propriedade ou outro direito de outra pessoa é passível de fazer uma compensação à outra parte pelos danos decorrentes desta.

(2) O mesmo dever é assumido por uma pessoa que cometer uma violação de uma lei que se destina a proteger outra pessoa. Se, de acordo com o conteúdo do estatuto, ele também pode ser violado sem culpa, porém, a responsabilidade por compensação existe apenas no caso de culpa (BUNDESREPUBLIK DEUTSCHLAND, 2002)².

Em suma, a previsão da normativa aqui em análise prevê que o descumprimento de suas regras irá gerar efeitos de indenização para o que havia sido então prejudicado, atribuindo concretude em forma de garantias normativas para com a coletividade. São consideradas Schutzgesetze as normas que digam respeito ao interesse, tanto individual, como coletivo, e o seu mais puro infringir atentaria contrariamente ao estatuto, configurando estado de lesão individual ou coletiva.

Da violação das Schutzgesetze nasce a responsabilidade e a obrigação de indenizar, não havendo necessidade de se comprovar o dano sofrido, individual, ou coletivamente (SALOMÃO FILHO, 2004). A presunção é que o mero transgredir de tais normas preestabelecidas significariam, objetivamente, uma tentativa de lesão aos interesses de terceiros. Cumpre ressaltar que foram reconhecidas no ordenamento alemão, como Schutzgesetze, sobretudo normas de proteção ao meio ambiente e de apoio à lealdade concorrencial.

As Schutzgesetze se fazem relevantes para esta discussão, pois se apresentam como normas protetoras de instituições, que embora possuidoras de efeito e eficácia coletiva, atingem também a esfera individual dos entes. Falam de um prejuízo institucional, que não se confunde "em absoluto com atribuição de caráter sancionatório à responsabilidade extracontratual", sendo que reconhece a existência de um dano a mais a ser reparado, que iria além dos prejuízos individuais (SALOMÃO FILHO, 2004, p. 10). É necessário o estabelecimento de critérios objetivos para a quantificação desses prejuízos institucionais, pois seus efeitos são amplamente subjetivos e atentam contra os interesses difusos e coletivos.

Tal como o instituto alemão aqui discutido, também a função social do contrato vem a possuir a mesma preocupação, a de proteger interesses, que seriam, a priori, indeterminados, mas que surtiriam efeitos diante de toda uma sociedade, como danos ambientais, danos aos espaços de uso público, e atos contrários à livre concorrência de mercado. Acerca desses cuidados, bem como de muitos outros, um bom contrato deve, não se basear, pois trata, sobretudo, de fazer lei entre as partes, mas se atentar de modo que seus efeitos alcancem a coletividade, mesmo que indiretamente, de forma responsável e coerente.

Por fim, anote-se que a limitação da liberdade de contratar reside junto aos limites dos interesses institucionais que se amparam sob os interesses difusos, devendo-se buscar um equilíbrio entre flexibilidade contratual e segurança jurídica

2 Cf. Original: § 823 Schadensersatzpflicht: (1)Wer vorsätzlich oder fahrlässig das Leben, den Körper, die Gesundheit, die Freiheit, das Eigentum oder ein sonstiges Recht eines anderen widerrechtlich verletzt, ist dem anderen zum Ersatz des daraus entstehenden Schadens verpflichtet. (2) Die gleiche Verpflichtung trifft denjenigen, welcher gegen ein den Schutz eines anderen bezweckendes Gesetz verstößt. Ist nach dem Inhalt des Gesetzes ein Verstoß gegen dieses auch ohne Verschulden möglich, so tritt die Ersatzpflicht nur im Falle des Verschuldens ein. 
(FARIAS; NELSON; BRAGA NETTO, 2019). Logo, aplicação do princípio da função social do contrato deve se fazer pragmática, na forma da lei, sempre que um respectivo contrato puder afetar, negativamente, e de alguma forma, os interesses institucionais, difusos ou coletivos, externos a esse.

\section{Conclusão}

Diante de toda discussão se procurou partir de uma ótica virtuosa e contemplativa acerca da figura ser humano, esse aqui entendido, enquanto objeto matriz para com os institutos aqui discutidos. Pretendeu-se emergir junto a uma reflexão que se amparasse, sobretudo, em uma atenção jurídico-humanizada, na qual o Direito, enquanto ciência, e na imagem de seus operadores, possuiria a nobre função de servir, proteger e moderar as ações dos indivíduos diante do grande guardachuva chamado de ordenamento jurídico.

Em uma perspectiva contratualista, procurou-se aqui refinar alguns conceitos. Para dignidade humana, por exemplo, foi possível atribuir alguns aportes a respeito de características que pareciam deixadas de lado. Visto como princípio jurídico ativo, tem a missão de matizar as normas jurídicas que tratam do ser humano, talhando-lhes uma feição que seja imbuída da mais verdadeira preocupação com o homem e seu meio de convívio, a sociedade. E muito embora um princípio jurídico não tenha, como foi dito, força normativa, deve se constituir como força motivadora do pensar jurídico.

Dentro da relação contratual, a dignidade humana ascende como influência junto das diretrizes tidas por probas no que tange ao agir dos seus partícipes. Esses devem atuar de acordo com princípios de probidade e de boa-fé que, embora entendidos como standards comportamentais, tais modos de agir só podem ser medidos e observados diante da realidade jurídica concreta. De toda sorte, parece que o agir com lealdade e com probidade contratual, e o dispensar do enriquecimento sem causa e do uso de desproporcional poder de resolução se embasa na mais pragmática manifestação de dignidade da pessoa humana dentro da seara contratualista.

Esse mesmo agir de acordo com os preceitos da boa-fé, aqui tida por objetiva, incorre em um procedimento contratual pautado pela lealdade, coerência e probidade, frise-se, antes, durante, e mesmo após o adimplemento final de um negócio jurídico. Trata-se de uma relação justaposta de direitos e deveres inerentes a ambas as partes, que se manifestam de maneira dinâmica diante do direito de exercer a autonomia privada. Um jogo de obrigações e responsabilidades, que devem ser sim, dogmaticamente interpretados, porém sem deixar uma demasiada ortodoxia jurídica transcender a atenção voltada aos aspectos concretos da vida humana, que seriam, não obstante, alterados de fato pelas circunstâncias de um determinado contrato.

Por fim, debateu-se sobre a função social do contrato, instituto esse que confere exterioridade à relação contratual, de modo que essa passa a ser vislumbrada tal como causadora de efeitos e de alteridades para indivíduos externos à relação contratual. Aqui, o tema do cuidado e da dignidade humana adquiri feição tanto mais complexa, ligando-se, sobretudo à defesa dos interesses difusos e da coletividade. Falar sobre os efeitos externos de uma determinada relação contratual, sem contemplar o entendimento acerca de interesses coletivos parece uma discussão carente de substância jurídica e humana e se faz necessário, assim, promover uma intensa e profunda discussão, que inclusive lance luz ao significado pragmático de interesses difusos, e os diferencie dos interesses individuais e coletivos.

De todo modo, a função social dos contratos se apresenta no contratualismo contemporâneo como uma diretriz de resguardo junto à defesa de garantias institucionais e metaindividuais. Relaciona-se, assim, a uma matriz solidária, cujo estar para o outro parece ser um novo e renovado ideal da autonomia de vontade, de modo a permear e, consequentemente, dar forma a um novo valor, fundamento e finalidade da ordem jurídica contemporânea.

Em suma, trata-se de refletir acerca da construção de um novo ideal que permita a partir de uma modificação junto ao pensar jurídico-contratual existente, colocar, sem pieguismos, os mais básicos e virtuosos interesses do ser humano à frente de uma agenda meramente econômica e focada nos atributos quantitativos de uma determinada realidade contratual. Tal como um contrato, um novo pensamento jurídico, que se ampare em verdadeira solidariedade ético-civil, deve causar efeito a todos, tanto aos que se propõem a pensar a Ciência do Direito, como àqueles que vivem, tão somente, em uma eterna busca de seus próprios direitos.

\section{Referências}

ANDRADE, A.G.C. O princípio fundamental da dignidade humana e sua concretização judicial. Rev. EMERJ, Direito Público, v.6, n.23, p.316-335, 2003.

BARBOSA, E.; COSTA, T.C.A.A concepção de dignidade humana em Ronald Dworkin: um problema de ética prática. Rev. Filosofia, v.13, n.1, p.306-316, 2016.

BAILO, G.L.; VIOLA, A.M.B.; MARICHAL, M.E. Bienes comunes en los primeros códigos civiles latinoamericanos. Rev. Direito $G V$, v.14, n.2, p.775-803, 2018.

BARROSO, L.R. Here, there, and everywhere: human dignity in contemporary law and in the transnational discourse. Boston College Int. Comp. Law Rev., v.35, n.2, p.331-394, 2012.

BRASIL. Assembléia Nacional Constituinte. 191-A. Constituição da República Federativa do Brasil de 1988. 5 out. 1988, Sec. 1, p. 1.

BRASIL. Senado Federal. 10.406. Código civil e legislação correlata. Subsecretaria de Edições Técnicas. 2008.

BUNDESREPUBLIK DEUTSCHLAND. Bürgerliches Gesetzbuch [1990] (Código Civil Alemão, versão de promugação). Bundesministerium der Justiz und für Verbraucherschutz. jan. 2002, Sec. 2909

DWORKIN, R. Justice for Hedgehogs. London: The Belknap Press of Harvard University Press, 2011.

FACHIN, L.E. Relações jurídicas, contratos e responsabilidade: uma liberdade, duas funcionalizações, três problematizações. 
Rev. Esc. Magistratura do TRF da $4^{a}$ Região, v.1, n.2, p.103-116, 2015.

FARIAS, C.C.; NELSON, R.; BRAGA NETTO, F. Manual de direito civil. Salvador: Juspodivm, 2019.

GADAMER, H.-G. Verdade e método. Petrópolis: Vozes, 1997.

GONÇALVES, H.A.C.; LOPES, M.H. A dignidade da pessoa humana e o valor social do trabalho. Rev. Direito Econ. Socioamb., v.4, n.607, p.129, 2013.

LOPES, J.R.L. Direitos humanos e tratamento igualitário: questões de impunidade, dignidade e liberdade. Rev. Bras. Ciênc. Soc., v.15, n.42, 2000.

MARINONI, L.G.; SARLET, I.W.; MITIDIERO, D. Curso de Direito Constitucional. São Paulo: Saraiva, 2017.

MARTINS-COSTA, J. A boa-fé no direito privado: critérios para a sua aplicação.São Paulo: Saraiva Jur, 2018.
MATTIETTO, L. Função social e diversificação do direito de propriedade. Rev. Fac. Direito Campos, v.6, n.6, p.155-168, 2005.

NALIN, P.R.R. A função social do contrato no futuro Código Civil brasileiro. Rev. Direito Privado, v.3, n.12, p.50-60, 2002.

REZENDE, C.L.; ZYLBERSZTAJN, D. Quebras contratuais e dispersão de sentenças. Rev. Direito GV, v.7, n.1, p.155-176, 2011.

ROSENVALD, N. A função social do contrato. Rev. MPMG Jurídico, v.2, n.9, p.10-20, 2007.

SALOMÃO FILHO, C. Função social do contrato: primeiras anotações. Rev. Tribunais, v.93, n.823, p.67-86, 2004.

SARLET, I.W. Dignidade da pessoa humana e direitos fundamentais na Constituição Federal de 1988. Porto Alegre: Livraria do Advogado, 2012.

TARTUCE, F. Manual de Direito Civil. São Paulo: Método, 2018. 